\title{
Pattern searches for the identification of putative lipoprotein genes in Gram-positive bacterial genomes
}

\author{
Iain C. Sutcliffe ${ }^{1}$ and Dean J. Harrington ${ }^{2}$
}

1 Fleming Building, Institute of Pharmacy, Chemistry and Biomedical Sciences, University of Sunderland Sunderland SR2 3SD, UK

2 Department of Biomedical Sciences, University of Bradford, UK

\author{
Author for correspondence: Iain C. Sutcliffe. Tel: +44 1915152995 . Fax: +44 1915153747. \\ e-mail: iain.sutcliffe@sunderland.ac.uk
}

\begin{abstract}
$\mathrm{N}$-terminal lipidation is a major mechanism by which bacteria can tether proteins to membranes and one which is of particular importance to Grampositive bacteria due to the absence of a retentive outer membrane. Lipidation is directed by the presence of a cysteine-containing 'lipobox' within the lipoprotein signal peptide sequence and this feature has greatly facilitated the identification of putative lipoproteins by gene sequence analysis. The properties of lipoprotein signal peptides have been described previously by the Prosite pattern PS00013. Here, a dataset of 33 experimentally verified Gram-positive bacterial lipoproteins (excluding those from Mollicutes) has been identified by an extensive literature review. The signal peptide features of these lipoproteins have been analysed to create a refined pattern, G+LPP, which is more specific for the identification of Gram-positive bacterial lipoproteins. The ability of this pattern to identify probable lipoprotein sequences is demonstrated by a search of the genome of Streptococcus pyogenes, in comparison with sequences identified using PS00013. Greater discrimination against likely false-positives was evident from the use of G+LPP compared with PS00013. These data confirm the likely abundance of lipoproteins in Gram-positive bacterial genomes, with at least 25 probable lipoproteins identified in S. pyogenes
\end{abstract}

Keywords: Streptococcus pyogenes, Bacillus subtilis, genomics, YidC, exported proteins

\section{INTRODUCTION}

The bacterial cell envelope is of major significance as the focal point for interaction between the bacterium and its environment, notably the host in the case of bacterial pathogens. Bacterial cell envelope proteins thus carry out numerous important functions including roles in adhesion, nutrient acquisition and a variety of interactions with host defences. In Gram-positive bacteria the matrix of peptidoglycan and other wall polymers surrounding the cell is not an efficient barrier to the passage of small macromolecules, due both to its inherent structural permeability and to its turnover during normal cell growth. Indeed, peptidoglycan may be sufficiently permeable as to allow the passage of

Abbreviations: Lpp, lipoprotein; MSD, membrane-spanning domain; SBP, substrate-binding protein. globular proteins of up to $\sim 50 \mathrm{kDa}$ in size (Demchick \& Koch, 1996; Dijkstra \& Keck, 1996). Consequently, in the absence of a retentive outer membrane, Grampositive bacteria have evolved distinct mechanisms for retaining proteins within their cell envelopes, including covalent linkage to the peptidoglycan and non-covalent binding to teichoic acids and other cell envelope polymers (Navarre \& Schneewind, 1999; Cossart \& Jonquieres, 2000; Janulczyk \& Rasmussen, 2001). Also significant among these mechanisms is membraneanchoring of bacterial lipoproteins (Lpps) by covalent N-terminal lipidation (Braun \& Wu, 1994; Sutcliffe \& Russell, 1995). Lpps in Gram-positive bacteria perform important roles as substrate-binding proteins (SBPs) in $\mathrm{ABC}$ transporter systems; in antibiotic resistance; in cell signalling; in protein export and folding; in sporulation and germination; in conjugation and various other functions (Sutcliffe \& Russell, 1995). Many of these Lpps, most notably the SBPs, perform functions equi- 


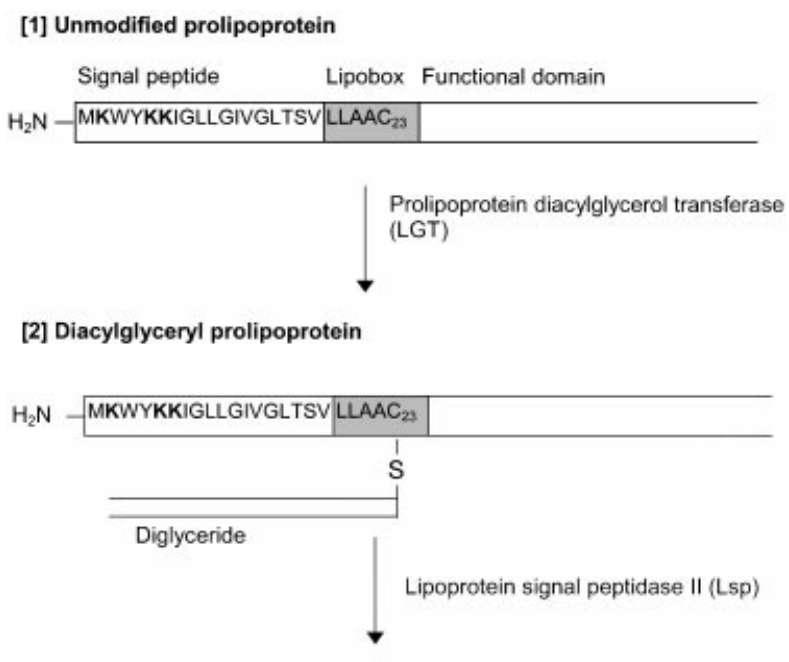

[3] Mature lipoprotein

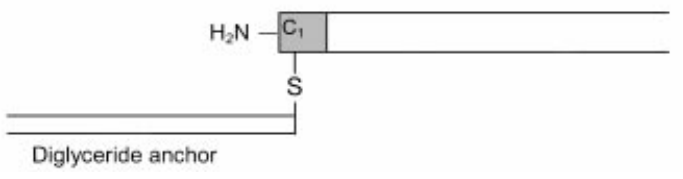

Fig. 1. Lipoprotein biosynthesis in Gram-positive bacteria. Lipid modification of prolipoproteins (by thioether linkage of diglyceride to the lipobox cysteine) is followed by signal peptide cleavage, generating the mature lipid-anchored lipoprotein. A possible further step whereby an additional fatty acid is amide-linked to the free amino terminus does not appear to occur in the low G + C Gram-positive bacteria and is not shown. The representative signal sequence shown is that of S. mutans MsmE (Sutcliffe et al., 1993) where $\mathrm{Cys}_{23}$ becomes $\mathrm{Cys}_{1}$ of the mature Lpp. Charged amino acids of the signal peptide n-region are highlighted in bold.

valent to those carried out by periplasmic proteins of Gram-negative bacteria.

The archetypal bacterial Lpp is the murein lipoprotein of Escherichia coli characterized by Braun and coworkers (reviewed in Braun \& Wu, 1994). Structural studies revealed that a diacylglycerol moiety is thioether linked to an $\mathrm{N}$-terminal cysteine of this Lpp and that this lipid group serves to orientate the protein by anchoring it to the inner leaflet of the outer membrane. Chemically identical lipid modifications have since been proposed, primarily on the basis of protein sequence analysis (see below), for a great many proteins in both Gram-positive and Gram-negative bacteria, although relatively few have received extensive biochemical characterization.

Biosynthesis of bacterial lipoprotein of the 'Braun' type proceeds via a well conserved pathway that is apparently unique to prokaryotes (Fig. 1). Following signal-peptidedirected export of the prolipoprotein (proLpp), the enzyme prolipoprotein diacylglycerol transferase (Lgt) uses phospholipid substrates and catalyses the addition of a diacylglycerol lipid unit onto the thiol of a crucial conserved cysteine which is located within a 'lipobox' motif at the cleavage region of the proLpp signal peptide (Sankaran et al., 1995; Qi et al., 1995). Subsequently, the signal peptide is removed by a specific lipoprotein signal peptidase II (Lsp) enzyme which cleaves within the lipobox to release the lipidated cysteine as the $\mathrm{N}$ terminus of the mature Lpp (Braun \& Wu, 1994; Sankaran \& Wu, 1995). These two steps have been confirmed to be necessary and sufficient for protein lipidation in Gram-positive bacteria (Zhao \& Wu, 1992; Witke \& Götz, 1995; Leskelä et al., 1999; Tjalsma et al., 1999a, b; Bengtsson et al., 1999; Petit et al., 2001). A third step, wherein the Lpp $\mathrm{N}$ terminus is further modified by addition of an amide-linked fatty acid, is apparently not conserved as homologues of the enzyme lipoprotein aminoacyl transferase are not found in the genomes of low G + C Gram-positive bacteria (Tjalsma et al., 1999a and our unpublished observations).

Processing of bacterial Lpp is thus dependent on both signal peptide features (directing protein export) and an appropriately placed lipobox (for prolipoprotein recognition and modification by Lgt and Lsp). The features of typical Lpp signal peptides are well established and consist of an $\mathrm{n}$-domain (containing the charged amino acids lysine and/or arginine), a central hydrophobic hdomain and a cleavage c-region (Klein et al., 1988; von Heijne, 1989; Braun \& Wu, 1994; Tjalsma et al., 2000). Sequence analysis of both Gram-negative and Grampositive Lpp signal peptides suggests these are typically shorter than those of secretory signal peptides and this mainly reflects the finding that their c-regions are shorter and typically contain apolar amino acids. As such, the cregion is effectively a continuation of the h-domain that is distinguished primarily by the sequence conservation preceding the invariant lipid-modified cysteine (von Heijne, 1989; Braun \& Wu, 1994). It is this sequence, typically Leucine ${ }_{-3}$-Alanine/Serine ${ }_{-2}$-Glycine/ Alanine $_{-1}$-Cysteine $_{+1}$ at positions -3 to +1 that is referred to as the lipobox sequence and the consensus pattern of amino acid usage has been documented in PROSITE under the pattern entry PS00013/PDOC00013 (http://www.expasy.ch/prosite/). The Prosite consensus pattern syntax (single letter amino acid code) describes the sequence motif determining lipidation as $\{$ DERK $\}(6)$-[LIVMFWSTAG] (2)-[LIVMFYSTAGCQ][AGS]-C wherein the permitted lipobox amino acids preceding the cysteine at positions -1 to -4 are indicated and the absence of charged residues (i.e. no $\mathrm{D}, \mathrm{E}, \mathrm{R}$ or $\mathrm{K}$ ) within the signal peptide h-region is prescribed. Furthermore, the pattern is subject to the application of additional rules: firstly, the cysteine must be between positions 15 and 35 of the sequence under consideration and secondly, there must be at least one lysine or one arginine in the first seven positions of the sequence. These rules localize the pattern to N-terminal sequences with n-regions characteristic of signal peptides.

Molecular genetic studies, and genome sequencing projects in particular, have identified a large number of putative Lpp genes on the basis of the presence of possible lipobox sequences at the $\mathrm{N}$ termini of translated 
protein sequences. Indeed, putative Lpps may represent at least $0 \cdot 5-8 \cdot 0 \%$ of the bacterial proteome (Chambaud et al., 1999; Tjalsma et al., 1999a; Haake, 2000). However, it remains possible that a significant proportion of these putative Lpps are 'false-positives', misidentified due to the coincident presence of a cysteine within the signal sequences of exported proteins or proteins targeted for insertion into plasma membranes. Thus it is desirable to develop a method for more accurately assigning sequences as putative Lpps. In this context it is significant that the lipobox amino acids are apparently subject to subtle taxon-specific restrictions. For example, the lipobox consensus defined from a dataset of 26 proven spirochaetal Lpps is distinctive in comparison to that of E. coli Lpps (Haake, 2000). Likewise, the lipobox sequences of a subset of Grampositive bacterial Lpp (proven and putative) were more restrictive than that described in the PS00013 pattern at the -3 and -2 positions (Sutcliffe $\&$ Russell, 1995). To investigate this further we have defined a dataset of Gram-positive bacterial Lpps for which there is experimental evidence to support lipidation, and performed sequence analyses to create a revised pattern for the identification of Gram-positive bacterial putative Lpps. This pattern has been applied to the genome of the human pathogen Streptococcus pyogenes, for which a novel inventory of putative Lpps is presented herein.

\section{METHODS}

Construction of a dataset of experimentally verified Grampositive bacterial Lpps. Several criteria were considered as evidence that a protein is lipidated in vivo. These included (1) metabolic labelling of the protein, in its source organism, with exogenously supplied radiolabelled fatty acid (normally palmitate, incorporation of which is typically detected by autoradiography following protein electrophoresis). This criterion excluded evidence of lipid radiolabelling of the protein following cloning into a heterologous Gram-negative bacterial host (usually E. coli) where the specificities of the Lpp processing enzymes may be subtly different. One exception within this criterion is the $\mathrm{Cu}, \mathrm{Zn}$ superoxide dismutase Lpp of Mycobacterium tuberculosis where non-denaturing electrophoresis indicated that the native membrane-associated enzyme activity is electrophoretically identical to that which has been radiolabelled with palmitate upon expression in $E$. coli (D'Orazio et al., 2001). (2) Inhibition of Lpp signal peptide processing by treatment with the antibiotic globomycin, which specifically inhibits Lsp (Inukai et al., 1978). (3) Chemical characterization of the purified protein. (4) Evidence that protein processing is disrupted by mutation in either Lgt or Lsp, or following site directed mutagenesis to replace the lipobox cysteine. Evidence that proteins remain detergentassociated on phase partitioning with Triton X-114 was not included as this may not adequately discriminate Lpp from peripheral membrane proteins or proteins tethered to membranes by other mechanisms. Furthermore, although Lpps are apparently highly abundant in Mollicutes (Razin et al., 1998; Chambaud et al., 1999), these Lpps were excluded from the present analysis as it has been previously noted that they may have distinctive signal peptide features in terms of both length (Edman et al., 1999) and their lipobox cleavage sites (Cleavinger et al., 1994, 1995). In this respect it is also notable that the putative Lgt sequences in the Mycoplasma genomes have distinctive sequence features (our unpublished observations). Moreover, variations in susceptibility to globomycin and alternative forms of lipidation were apparent in Acholeplasma laidlawii (Nyström et al., 1986; Nyström \& Wieslander, 1992). It was thus considered that these Lpps represent an abundant, distinctive subset that should be considered separately to avoid artificially polarizing the dataset. Following an extensive review of the available literature, 33 proteins that satisfied at least one of the above described criteria were identified as proven Lpps (Table 1).

Identification of Lpp sequences by pattern searching. Pattern documentation for the prokaryotic membrane lipoprotein lipid attachment site (PS00013) was obtained from the Prosite website (Falquet et al., 2002; http://www.expasy.ch/prosite/). Pattern searches of the SWISS-PROT and TrEMBL databases were performed using the ScanProsite tool (http:// ca.expasy.org/tools/scanprosite/), restricting the searches to entries specific for Bacillus subtilis or S. pyogenes. Protein sequences for further analyses were retrieved from SWISSPROT and TrEMBL.

Protein primary sequence analyses. Membrane spanning domains (MSDs) in protein sequences were predicted using TMpred (Hofmann \& Stoffel, 1993; http://www.ch.embnet. org/software/TMPRED_form.html), set to a minimum length of 14 aa for the hydrophobic domains. Signal peptide analyses were performed using the refined hidden Markov model version 2.0 of SignalP (Nielsen et al., 1997; Nielsen \& Krogh, 1998; http://www.cbs.dtu.dk/services/SignalP-2.0/). Although Lpp signal peptide cleavage sites are not predicted, the graphical display from this service was particularly useful as it provided an indication of the lengths of predicted signal peptide n- and h-regions relative to the position of the possible lipobox cysteine. Where sequence features required further clarification, other methods for predicting transmembrane domains were also applied including TopPred2 (Claros \& von Heijne, 1994; http://bioweb.pasteur.fr/seqanal/interfaces/ toppred.html) and DAS (Cserzo et al., 1997; http://www. sbc.su.se/ $\sim$ miklos/DAS /).

Sequences homologous to the putative Lpps were identified by BLAST searches (Altschul et al., 1997) using the National Center for Biotechnology Information tBLASTn server (http://www.ncbi.nlm.nih.gov/BLAST/), typically with the sequence filtering option switched off and the Expect value set at $0 \cdot 001$.

Access to sequence annotation of the $S$. pyogenes and Streptococcus pneumoniae genomes was obtained via the Entrez Genomes facility at the National Center for Biotechnology Information (http://www.ncbi.nlm.nih.gov/ PMGifs/Genomes/micr.html). Finally, other general searches were performed using the PEDANT genome sequence analysis tool (Frishman et al., 2001; http://pedant.gsf.de/).

Criteria for exclusion of sequences as false-positives unlikely to encode Lpps. The N-terminal features of putative Lpps were individually analysed to determine whether they might be considered false-positives using the following criteria. Firstly, TMpred was used to determine the position of the most N-terminal MSD and also the number of additional MSDs. Those sequences where either an MSD was clearly absent or the most N-terminal MSD clearly extended beyond the lipobox cysteine (e.g. sequences likely to direct insertion of integral membrane proteins) were considered possible falsepositives. The detection using TMpred of additional MSDs beyond the lipobox cysteine was not considered sufficient justification for excluding sequences, since both the CtaC and 
Table 1. Gram-positive bacterial lipoproteins for which both sequence data and experimental evidence for lipidation is available

Categories for the experimental verification of protein lipidation are numbered the same as in Methods i.e. (1) metabolic labelling of the protein, in its source organism, with exogenously supplied radiolabelled fatty acid; (2) inhibition of Lpp signal peptide processing by treatment with the antibiotic globomycin, which specifically inhibits Lsp; (3) chemical characterization of the purified protein; (4) evidence that protein processing is disrupted by mutation of the biosynthetic enzymes Lgt or Lsp, or following site directed mutagenesis to replace the lipobox cysteine.

\begin{tabular}{|c|c|c|c|c|c|}
\hline \multirow[t]{2}{*}{ Source organism and protein } & \multicolumn{4}{|c|}{ Experimental evidence } & \multirow[t]{2}{*}{ Reference } \\
\hline & 1 & 2 & 3 & 4 & \\
\hline Alicyclobacillus acidocaldarius MalE & + & & & & Hermann et al. (1996); Hülsmann et al. (2000) \\
\hline Bacillus cereus BlaZ & + & + & + & & Nielsen \& Lampen $(1982,1983)$ \\
\hline Bacillus licheniformis $\mathrm{BlaP}$ & + & + & + & & Nielsen \& Lampen (1982) \\
\hline Bacillus sp.pS3 CccA & & & + & & Fujiwara et al. (1993) \\
\hline B. subtilis $\mathrm{CtaC}$ & & & & + & Bengtsson et al. (1999) \\
\hline B. subtilis KapB & & & & + & Dartois et al. (1997) \\
\hline B. subtilis OpuAC SBP & & + & & + & Kempf et al. (1997) \\
\hline B. subtilis PrsA & + & & & + & $\begin{array}{l}\text { Kontinen \& Sarvas (1993); Tjalsma et al. } \\
\text { (1999a) }\end{array}$ \\
\hline B. subtilis PstS (YqgG) & & & & + & Antelmann et al. (2001) \\
\hline B. subtilis QoxA & & & & + & Antelmann et al. (2001) \\
\hline Corynebacterium glutamicum $\mathrm{CtaC}$ & & & & + & Sakamoto et al. (2001) \\
\hline Heliobacterium gestii ChyA (c553) & & & + & & Albert et al. (1998) \\
\hline Lactococcus lactis PrtM & + & & & + & Haandrikman et al. (1991) \\
\hline Mycobacterium bovis MPB83 & & & & + & Vosloo et al. (1997) \\
\hline Mycobacterium intracellulare MI43 & + & & & & Nair et al. (1993) \\
\hline Mycobacterium tuberculosis $19 \mathrm{kDa}$ & + & & & & $\begin{array}{l}\text { Ashbridge et al. (1989); Young \& Garbe } \\
\text { (1991) }\end{array}$ \\
\hline M. tuberculosis PhoS & + & & & & $\begin{array}{l}\text { Andersen \& Hansen (1989); Young \& Garbe } \\
\text { (1991) }\end{array}$ \\
\hline M. tuberculosis $\mathrm{Cu}, \mathrm{Zn} \mathrm{SOD}$ & + & & & & D’Orazio et al. (2001) \\
\hline Staphylococcus aureus Bla & + & + & + & & Nielsen \& Lampen (1982) \\
\hline Staphylococcus carnosus ModA & + & & & & Neubauer et al. (1999) \\
\hline Staphylococcus epidermidis SitC & + & & & & Cockayne et al. (1998) \\
\hline Streptococcus equi HAP & & + & & & $\begin{array}{l}\text { Chanter et al. (1999); I. Sutcliffe \& N. } \\
\text { Chanter, unpublished }\end{array}$ \\
\hline Strep. equi LppC & & + & & & Hamilton et al. (2000) \\
\hline Strep. equi MBL & & + & & & Harrington et al. (2000) \\
\hline Streptococcus gordonii SarA (HppA) & + & & & & Jenkinson et al. (1996) \\
\hline Streptococcus mutans MsmE & + & + & & & Sutcliffe et al. (1993) \\
\hline Streptococcus pneumoniae AmiA & + & & & & Alloing et al. (1994) \\
\hline Strep. pneumoniae AliA & + & & & & Alloing et al. (1994) \\
\hline Strep. pneumoniae AliB & + & & & & Alloing et al. (1994) \\
\hline Streptococcus pyogenes LppC & & + & & & Gase et al. (1997) \\
\hline Streptomyces chrysomallus FKBP33 & + & & & & Pahl \& Keller (1994) \\
\hline Streptomyces reticuli CebE & + & + & & & Schlosser \& Schremf (1996) \\
\hline Thermoanaerobium ethanolicus XylF & + & & & & Erbeznik et al. $(1998 \mathrm{a}, \mathrm{b})$ \\
\hline
\end{tabular}

the QoxA proven Lpps have two additional MSDs predicted beyond their N-terminal lipid anchors (Bengtsson et al., 1999; Sakamoto et al., 2001; Antelmann et al., 2001), as does the Mycoplasma pneumoniae $\mathrm{F}_{0} \mathrm{~F}_{1}$ ATPase (Pyrowolakis et al., 1998).

Sequences were also analysed using SignalP. Those sequences where an h-region was typically predicted to end within 2 aa of the lipobox cysteine were retained as possible Lpps.
Cumulatively, those sequences where signal peptide features were absent altogether and/or the lipobox cysteine was clearly internal rather than terminal to an h-region/MSD were considered to be likely false-positives. Those sequences where further clarification was needed were investigated using various other servers for predicting transmembrane regions (notably TopPred2 and DAS) and a consensus taken as to the position of the putative lipobox cysteine relative to the length of the first predicted MSD. 


\section{RESULTS AND DISCUSSION}

\section{Analysis of the signal peptide and lipobox features of experimentally verified Gram-positive bacterial Lpps}

An extensive literature search identified 33 experimentally verified Lpps from Gram-positive bacteria (Table 1). Analysis of the lipobox features of these proteins (see Tables 2 and 3) confirmed previously observed preferences (Braun \& Wu, 1994; Sutcliffe \& Russell, 1995), notably in the high frequency of leucine at the -3 position, and alanine or serine at -2 of the lipobox. However, compared with the PS00013 pattern, some deviations and restrictions were apparent. Alanine and glycine were the only amino acids noted at the -1 position, as previously noted for proven Lpps generally (von Heijne, 1989). Significantly, it was observed that the B. subtilis KapB sequence contains a glutamic acid (E) at position -4 of its lipobox, an occurrence proscribed by the PS00013 pattern.

Analysis of this $33 \mathrm{Lpp}$ dataset indicated that the nregions had a mean length of $6.7 \pm 3.5$ and a range of 3-15 aa. Notably, two proven Lpps (KapB of B. subtilis and MI43 of Mycobacterium intracellulare) had N termini with no arginine or lysines in the first 7 aa, which is contradictory to the PS00013 additional rules. The mean h-region length was $12 \cdot 1 \pm 2 \cdot 3$ aa, with a range from 6-20 aa. These figures are in good agreement with the h-region features reported for the putative Lpp of B. subtilis (Tjalsma et al., 2000). The mean cysteine position was $24.0 \pm 3.6$ (range 17-33) confirming that these signal peptides are typically shorter than those directing protein export in Gram-positive bacteria, for which a mean length of 32 has been reported (Nielsen $e t$ al., 1997). It was also informative to consider the length of the membrane-spanning regions of these signal peptides i.e. the h-region plus the 5 typically apolar amino acids of the lipobox motif. This indicated the mean length of the combined $\mathrm{h}$ - and c-regions to be $17 \cdot 1$ aa, which is sufficient to span a typical bilayer membrane. These data suggest that the active site of the Lgt enzyme most likely interacts with the lipobox cysteine at the outer face of the cytoplasmic membrane. Sequence alignments of proven and putative Lgt enzymes from a wide range of taxa indicate that the most highly conserved residues are likely to be positioned at this interface (A. Hamilton, I. C. Sutclifffe. \& D. J. Harrington, unpublished observations), as has been predicted for the critical aspartates in the active site of Lsp (Tjalsma et al., 1999b).

Given that certain proven Lpps had signal peptide sequences features clearly contradictory to those described by the PS00013 pattern, and that additional discrimination against false-positives is likely to result from the derivation of a taxon-specific pattern, a modified pattern was defined for the proven Lpp signal peptide sequences of Gram-positive bacteria (Table 2). This pattern, $<[\mathrm{MV}]-\mathrm{X}(0,13)-[\mathrm{RK}]-\{\mathrm{DERKQ}\}(6,20)-$ [LIVMFESTAG]-[LVIAM]-[IVMSTAFG]-[AG]-C (using Prosite syntax), was termed G+LPP (Table 3).
To test the utility of this pattern, it was applied to a search of the genome of $B$. subtilis, as signal peptide dependent export has been extensively studied in this organism (Tjalsma et al., 2000). A set of 103 putative Lpps of $B$. subtilis were identified by a pattern search with PS00013, whereas only 61 probable Lpps and the six proven Lpps of this organism were identified using the G + LPP pattern. The G + LPP pattern gave a greater discrimination (four rather than sixteen hits) against sequences considered false-positives using the criteria described herein (data not shown). Cumulatively, it was considered that the advantage of using the G+LPP pattern was the greater confidence that could be placed in the predictions that conforming sequences are indeed likely to be Lpps.

\section{Application of the G + LPP pattern to analysis of the $S$. pyogenes genome}

$S$. pyogenes sequences in the SWISS-PROT/TrEMBL database containing the PS00013 pattern were identified and compared to those identified in a similar pattern search with G+LPP (Table 4). The PS00013 search identified 36 sequences of which nine $(25 \%)$ were excluded as unlikely Lpps (false-positives) using the criteria described herein. The G + LPP pattern search again proved more discriminatory than PS00013 in that 26 sequences were identified, of which only one $(4 \%)$ was considered as an unlikely Lpp. Thus eight out of nine $(89 \%)$ of the unlikely Lpps initially identified using PS00013 were excluded (Table 4). Both searches identified the only previously identified proven Lpp, the putative acid phosphatase LppC (Gase et al., 1997; Malke, 1998). Similarly, both searches also identified the Lbp laminin-binding protein (Terao et al., 2002) and three previously identified SBPs (Podbielski et al., 1996; Podbielski \& Leonard, 1998; Janulczyk et al., 1999), all of which have previously been considered putative Lpps. Notably, however, the search with G + LPP identified an additional putative SBP sequence (Spy0903) that had been excluded using PS00013 on account of the extended n-region features of this signal sequence.

The 24 probable Lpps identified represent $\sim 1.5 \%$ of the $S$. pyogenes proteome. This is comparable to the identification of 36 putative Lpps $(\sim 1.6 \%$ of the proteome) in the S. pneumoniae genome (Tettelin et al., 2001). Indeed, many of the putative Lpps of $S$. pyogenes have a pneumococcal putative Lpp homologue (the online version of this paper at http://mic.sgmjournals.org contains a supplementary table showing the outputs from BLAST searches with the $S$. pyogenes putative Lpp sequences) and $\sim 60 \%$ have a putative Lpp homologue in the B. subtilis genome. As in S. pneumoniae and other Gram-positive bacteria, the majority of these probable Lpps are putative SBPs predicted to be involved in the transport of substrates such as amino acids/peptides, iron/ferrichromes, other metal ions, phosphate and sugars. The abundance of putative amino acids/peptide transporters has been noted previously (Ferretti et al., 2001). One putative SBP, Spy1228, belongs to a recently 
Table 2. Signal peptide features of the proven Gram-positive Lpp dataset

Signal peptide features have been separated to illustrate the charged n-region amino acids (bold), the hydrophobic h-region sequence and the lipobox preceding the lipidated cysteine.

\begin{tabular}{|c|c|c|c|c|c|c|c|c|}
\hline \multirow[t]{2}{*}{ Protein } & \multirow{2}{*}{$\begin{array}{l}\text { n-region sequence } \\
\quad(\text { no. aa) }\end{array}$} & \multirow{2}{*}{$\begin{array}{l}\text { h-region sequence } \\
\quad(\text { no. aa) }\end{array}$} & \multicolumn{6}{|c|}{ Lipobox (c-region) } \\
\hline & & & -4 & -3 & -2 & -1 & $\mathrm{C}_{\mathrm{n}}^{*}$ & +2 \\
\hline A. acidocaldarius MalE & $\operatorname{VSVRR}(5)$ & WGIVSTGVAALVLAGG (16) & A & $\mathrm{I}$ & A & G & C26 & G \\
\hline Bacillus cereus BlaZ & MFVLNKFFTNSHYKK (15) & IVPVVLLSCA $(10)$ & $\mathrm{T}$ & $\mathrm{L}$ & $\mathrm{I}$ & G & C30 & $\mathrm{S}$ \\
\hline B. licheniformis BlaP & MKLWFSTLKLKK (12) & AAAVLLFSCV (10) & A & $\mathrm{L}$ & A & G & $\mathrm{C} 27$ & $\mathrm{~A}$ \\
\hline Bacillus sp. pS3 CccA & MKWK (4) & LAAMFLGVSL (10) & $\mathrm{A}$ & $\mathrm{L}$ & A & $\mathrm{A}$ & C19 & G \\
\hline B. subtilis $\mathrm{CtaC}$ & MVKHWR (6) & LILLLALVPL $(10)$ & $\mathrm{L}$ & $\mathrm{L}$ & $\mathrm{S}$ & G & $\mathrm{C} 21$ & G \\
\hline B. subtilis KapB & MSTFETGSIVKGFYK (15) & TGVYIG $(6)$ & $\mathrm{E}$ & I & $\mathrm{T}$ & $\mathrm{A}$ & $\mathrm{C} 26$ & $\mathrm{R}$ \\
\hline B. subtilis OpuAC SBP & $\operatorname{MLKK}(4)$ & IIGIGVSAMLAL (12) & S & $\mathrm{L}$ & $\mathrm{A}$ & $\mathrm{A}$ & $\mathrm{C} 21$ & G \\
\hline B. subtilis PrsA & MKK (3) & IAIAAITATSIL (12) & A & $\mathrm{L}$ & $\mathrm{S}$ & $\mathrm{A}$ & $\mathrm{C} 20$ & S \\
\hline B. subtilis PstS & MKKNK (5) & LVLMLLMAAFMM (12) & $\mathrm{I}$ & A & A & $\mathrm{A}$ & $\mathrm{C} 22$ & G \\
\hline B. subtilis QoxA & MVIFLFRALK $(10)$ & PLLVLALLTVVF (12) & $\mathrm{V}$ & $\mathrm{L}$ & G & G & $\mathrm{C} 27$ & $\mathrm{~S}$ \\
\hline $\begin{array}{l}\text { Corynebacterium glutamicum } \\
\text { CtaC }\end{array}$ & MEQQNKRGLKRK (12) & ALLGGVLGLGGL (12) & A & M & A & G & C29 & $\mathrm{E}$ \\
\hline Heliobacterium gestii ChyA & MKNLK (5) & LIGIAAVMGLSMV (13) & A & $\mathrm{L}$ & $\mathrm{T}$ & A & $\mathrm{C} 23$ & $\mathrm{~N}$ \\
\hline Lactococcus lactis PrtM & MKKKMRLK (8) & VLLASTATALL (11) & $\mathrm{L}$ & $\mathrm{L}$ & $\mathrm{S}$ & G & $\mathrm{C} 24$ & Q \\
\hline Mycobacterium bovis MPB83 & MINVQAK (7) & PAAAASLAAIAIA (13) & $\mathrm{F}$ & $\mathrm{L}$ & A & G & $\mathrm{C} 25$ & $S$ \\
\hline $\begin{array}{l}\text { Mycobacterium intracellulare } \\
\text { MI43 }\end{array}$ & MSASCAVPRLTR (12) & FAVFAVAGATAL (12) & $S$ & $\mathrm{~L}$ & S & A & $\mathrm{C} 29$ & G \\
\hline $\begin{array}{l}\text { Mycobacterium tuberculosis } \\
19 \mathrm{kDa}\end{array}$ & MKR (3) & GLTVAVAGAAILVA (14) & G & $\mathrm{L}$ & $\mathrm{S}$ & G & $\mathrm{C} 22$ & $\mathrm{~S}$ \\
\hline M. tuberculosis PhoS & $\operatorname{MKIR}(4)$ & LHTLLAVLTAAPLLL (15) & A & A & A & G & $\mathrm{C} 24$ & G \\
\hline M. tuberculosis $\mathrm{Cu}, \mathrm{Zn} \mathrm{SOD}$ & MPKPADHR (8) & NHAAVSTSVLSALFLGAGAA (20) & $\mathrm{L}$ & $\mathrm{L}$ & S & A & C33 & $\mathrm{S}$ \\
\hline $\begin{array}{l}\text { Staphylococcus epidermidis } \\
\text { SitC }\end{array}$ & MKK (3) & ILALAIAFLI (10) & I & $\mathrm{L}$ & $\mathrm{A}$ & A & C18 & G \\
\hline Staphylococcus aureus Bla & MKK (3) & LIFLIVIAL (9) & $\mathrm{V}$ & $\mathrm{L}$ & $S$ & A & C17 & $\mathrm{N}$ \\
\hline $\begin{array}{l}\text { Staphylococcus carnosus } \\
\text { ModA }\end{array}$ & MKIK (4) & HFLIALVAICL (11) & $\mathrm{V}$ & $\mathrm{L}$ & A & G & $\mathrm{C} 20$ & $S$ \\
\hline Streptococcus equi HAP & MTVLGTKACKR (11) & LGLAAVTLASVA (12) & A & $\mathrm{L}$ & M & A & $\mathrm{C} 28$ & G \\
\hline Streptococcus equi LppC & MTSKK (5) & ILNLVSLGLSLV(12) & $\mathrm{L}$ & $\mathrm{I}$ & $\mathrm{F}$ & G & $\mathrm{C} 22$ & $\mathrm{~T}$ \\
\hline Streptococcus equi MBL & MKKK (4) & LSLALSAFLAVF (12) & M & $\mathrm{L}$ & $\mathrm{V}$ & $\mathrm{A}$ & C21 & $\mathrm{S}$ \\
\hline $\begin{array}{l}\text { Streptococcus gordonii SarA } \\
\text { (HppA) }\end{array}$ & MKKGK (5) & ILALAGVALLATG (13) & $\mathrm{V}$ & $\mathrm{L}$ & A & A & $\mathrm{C} 23$ & S \\
\hline Streptococcus mutans MsmE & MKWYKK (6) & IGLLGIVGLTSV (12) & $\mathrm{L}$ & $\mathrm{L}$ & A & A & $\mathrm{C} 23$ & $\mathrm{~N}$ \\
\hline $\begin{array}{l}\text { Streptococcus pneumoniae } \\
\text { AmiA }\end{array}$ & MKKNR (5) & VFATAGLVLLAAG (13) & $\mathrm{V}$ & $\mathrm{L}$ & A & A & $\mathrm{C} 23$ & $S$ \\
\hline Strep. pneumoniae AliA & MKSSK (5) & LLALAGVTLLAAT (13) & $\mathrm{T}$ & $\mathrm{L}$ & A & A & $\mathrm{C} 23$ & S \\
\hline Strep. pneumoniae AliB & MKKSKSK (7) & YLTLAGLVLGTGV (13) & $\mathrm{L}$ & $\mathrm{L}$ & $\mathrm{S}$ & A & $\mathrm{C} 25$ & G \\
\hline $\begin{array}{l}\text { Streptococcus pyogenes LppC } \\
\text { SPy } 1882\end{array}$ & MKSKK (5) & VVSVISLTLSLF (12) & $\mathrm{L}$ & $\mathrm{V}$ & $\mathrm{T}$ & G & $\mathrm{C} 22$ & A \\
\hline $\begin{array}{l}\text { Streptococcus chrysomallus } \\
\text { FKBP33 }\end{array}$ & VRR (3) & IAGLLVAPLLLL (12) & $S$ & A & $\mathrm{V}$ & A & $\mathrm{C} 20$ & G \\
\hline Streptococcus reticuli $\mathrm{CebE}$ & MRTSIRRSQR (10) & LMALAAVAALTTG (13) & $\mathrm{L}$ & $\mathrm{L}$ & A & G & $\mathrm{C} 28$ & A \\
\hline $\begin{array}{l}\text { Thermoanaerobium } \\
\text { ethanolicus XylF }\end{array}$ & MFKKVSKK (7) & FALLIVAMFTLGI (13) & $\mathrm{I}$ & $\mathrm{L}$ & $S$ & G & C26 & A \\
\hline
\end{tabular}

* No. of the lipidated cysteine.

recognized family of lipoproteins (Rosati et al., 1999) which also includes the TcsA CD4 $+\mathrm{T}$ cell-stimulating antigen of Listeria monocytogenes (Campbell \& Shastri, 1998). A further S. pyogenes putative SBP Lpp belonging to this family (Spy0163, 65\% identical to Spy1228) was identified as a 'false-negative' (see below). Whilst Spy1228 (like its pneumococcal homologue SP0845) is adjacent to other components of a putative ABC sugar 
Table 3. Summarized signal peptide features, lipobox amino acid frequencies for 33 proven Gram-positive bacterial Lpps and pattern comparison with Prosite PS00013

The frequency of amino acid usage in the lipobox region is indicated and the deduced patterns (converted to Prosite syntax) for each signal peptide region are shown in comparison to the appropriate part of the PS00013 pattern.

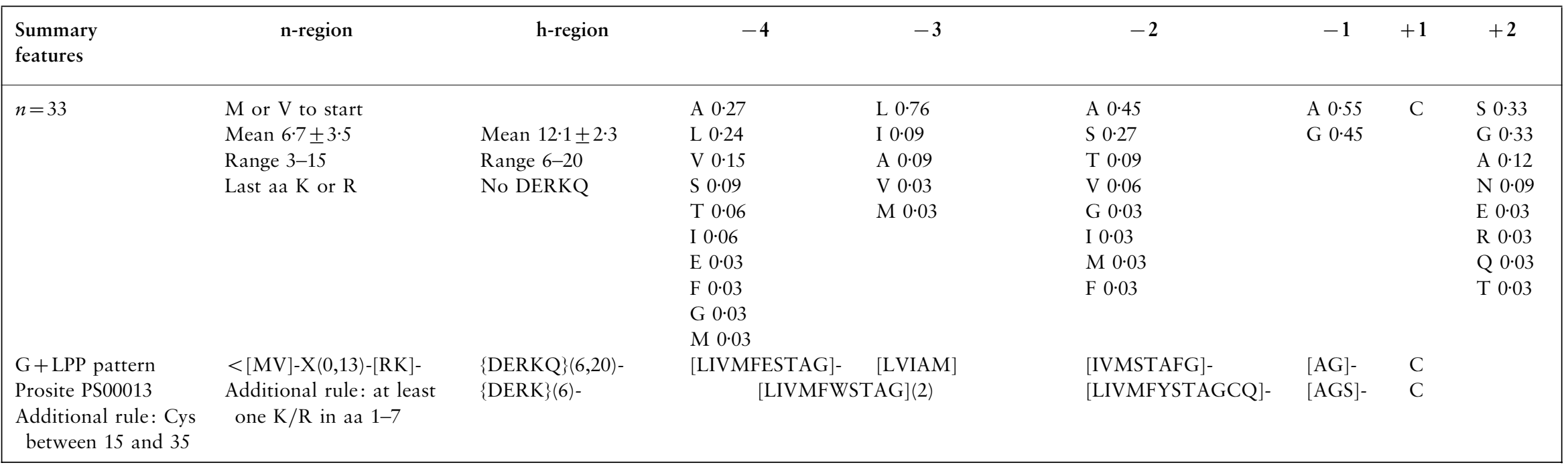


Table 4. Signal peptide analysis of S. pyogenes proteins identified by pattern searches with PS00013 and G + LPP

\begin{tabular}{|c|c|c|c|c|c|c|c|}
\hline Sequence & Signal peptide features* & $\begin{array}{l}\text { Cys } \\
\text { no. }\end{array}$ & h-region $\dagger$ & $\begin{array}{c}\text { Other } \\
\text { MSDs } \ddagger\end{array}$ & SignalP $\mathbb{S}$ & $\mathrm{G}+\mathrm{LPP} \|$ & Verdict \\
\hline Spy1882 & MKSKKVVSVISLTLSLFLVTGCA & 22 & $6-23$ & 0 & G21 & + & Proven \\
\hline OppA & MKKSKWLAAVSVAILSVSALAACG & 23 & $6-24$ & 0 & G24 & + & Probable \\
\hline Spy0210 & MGVMMK@KIKILTVIGLMTVGMSACH & 25 & $11-26$ & 0 & $\mathrm{C} 25$ & + & Probable \\
\hline Spy0247 & MRKVLRVKKNIKIARIVPLVLLLVACG & 26 & $16-34$ & 4 & G27 & + & Probable \\
\hline Spy0252 & MNMKKLASLAMLGASVLGLAACG & 22 & $9-24$ & 0 & G23 & + & Probable \\
\hline Spy0317 & MIKKQYLGRATIALASTLVLAACG & 23 & $6-26$ & 0 & G24 & + & Probable \\
\hline Spy0319 & MSEKKWIGIVGIALASTVLVACS & 22 & $6-21$ & 0 & $\mathrm{C} 22$ & + & Probable \\
\hline Spy0351 & MKLTLNRILFSGLALS ILLTLTGCV & 24 & $8-26$ & 4 & V25 & + & Probable \\
\hline Spy0385 & MKKLTLLLTLCLTTITLIACG & 20 & $4-21$ & 0 & G21 & + & Probable \\
\hline Spy0453 & MGKRMSLILGAFLSVFLLVACS & 21 & $7-22$ & 0 & S22 & + & Probable \\
\hline Spy0604 & MNKRFKTGFLALVAMLLVACS & 20 & $8-24$ & 0 & $\mathrm{C} 20$ & + & Probable \\
\hline Spy0857 & MTKKKGKLVLISLFVLAACL & 19 & $8-26$ & 0 & G21 & + & Probable \\
\hline Spy09039 & MLYYSYLNKGVTMKKSVTLLS I GLASLLLAACA & 32 & $18-33$ & 0 & A31 & + & Probable \\
\hline Spy1228 & MNKKFIGLGLASVAVLSLAACG & 21 & $5-22$ & 0 & G22 & + & Probable \\
\hline Spy1245 & MKMKKKFFLLSLLALSTFFLSACS & 23 & $7-27$ & 0 & S25 & + & Probable \\
\hline Spy1274 & MI IKKRTVAILAIASSFFLVACQ & 22 & $9-25$ & 0 & $\mathrm{C} 22$ & + & Probable \\
\hline Spy1290 & MTKKHLLTLLLISFFTSFLVACS & 22 & $6-22$ & 0 & A21 & + & Probable \\
\hline Spy1294 & MKSWQKVIVGGASLTLASTLLVGCG & 24 & $7-24$ & 0 & $\mathrm{C} 24$ & + & Probable \\
\hline Spy1390 & MKNSNKLIASVVTLASVMALAACQ & 23 & $7-23$ & 0 & $\mathrm{~A} 22$ & + & Probable \\
\hline Spy1405 & MLRKKKTTIVGI ILGMMIVTLLVGCL & 25 & $9-28$ & 0 & L26 & + & Probable \\
\hline Spy1558 & MKKGLLVTTGLACLGLLTACS & 20 & $4-20$ & 1 & S21 & + & Probable \\
\hline Spy1795 & MIKRCKGIGLALMAFFLVACV & 20 & $8-25$ & 1 & $\mathrm{~V} 21$ & + & Probable \\
\hline Spy 2000 & MSKYLKYFSIITLFLTGLILVACQ & 23 & $7-23$ & 0 & $\mathrm{~A} 22$ & + & Probable \\
\hline Spy 2007 & MKKGFFLMAMVVSLVMIAGCD & 20 & $3-20$ & 0 & $\mathrm{C} 20$ & + & Probable \\
\hline Spy 2037 & MKQMNKLITGVVTLATVVTLSACQ & 23 & $7-23$ & 0 & $\mathrm{~A} 22$ & + & Probable \\
\hline Spy1361 & MKTKKVIILVGLLLSSQLTLIACQ & 23 & $7-23$ & 0 & $\mathrm{C} 23$ & - & Possible \\
\hline Spy1972 & MKKKVNQGSKRYQYLLKKWGIGFVIAATGTVVLGCT & 35 & $19-36$ & 1 & $\mathrm{C} 35$ & - & Possible \\
\hline Spy2066\# & MINKKISLGVLSILTAFSLQSVSYACT & 26 & $6-32$ & 0 & S18 & - & Possible \\
\hline $\begin{array}{c}\text { Spy0257 } \\
\text { NanH }\end{array}$ & MTDLTKYQGI IPAFYACY & 17 & 0 & 3 & Absent & - & Unlikely \\
\hline $\begin{array}{l}\text { Spy0422 } \\
\text { MetS }\end{array}$ & MMKKPFYITTPIYYPSGKLHIGSAYTTIACD & 30 & 0 & 3 & Absent & - & Unlikely \\
\hline Spy0428 & MLKKRYQLAIVLLLSCF & 16 & $6-23$ & 0 & $\mathrm{I} 20$ & - & Unlikely \\
\hline $\begin{array}{c}\text { Spy0456 } \\
\text { MtsC }\end{array}$ & MSMKFFEGLMSYHFLQNALITAVVIGIVSGAVGCF & 34 & $18-38$ & 6 & Absent & - & Unlikely \\
\hline $\begin{array}{c}\text { Spy0764 } \\
\text { EpuA }\end{array}$ & MTNGLKYVLEQMLLLFI IAALACL & 23 & $17-31$ & 0 & $\mathrm{I} 28$ & - & Unlikely \\
\hline Spy1094 & MNNRHKRR $Q \mathbf{K R K A F T L I N L I L L F A C I ~}$ & 25 & $13-36$ & 0 & F33 & + & Unlikely \\
\hline $\begin{array}{l}\text { Spy1150 } \\
\text { Nox }\end{array}$ & MSKIVVVGANHAGTACI & 16 & 0 & 2 & Absent & - & Unlikely \\
\hline $\begin{array}{l}\text { Spy1209 } \\
\text { PdxK }\end{array}$ & MKRIVVANDLVGVGKVALSAS I PLMASCL & 28 & $10-30$ & 1 & Absent & - & Unlikely \\
\hline $\begin{array}{l}\text { Spy1593 } \\
\text { permease }\end{array}$ & MEKKKKVEKVNVRTFDRKTNAIFNILIGLFAISCI & 34 & $22-44$ & 5 & $\mathrm{~F} 40$ & - & Unlikely \\
\hline
\end{tabular}

*n-region lysine and arginines are highlighted in bold.

†The position of the most N-terminal MSD identified using TMpred was determined.

$\ddagger$ Total number of other MSDs predicted by TMpred.

$\mathbb{S}$ Amino acid position predicted to represent the end of the $n / h$ region using SignalP.

$\|+$ indicates sequences also identified by pattern searching with G+LPP.

I Putative SBP sequence identified on searching with G+LPP but not by PS00013.

\# The signal sequence features of this sequence are unclear. 
transporter in the $S$. pyogenes genome, Spy0163 is not (Ferretti et al., 2001).

A second major functional category of $S$. pyogenes Lpps were those that may be involved in protein export and extracytoplasmic folding. Thus two homologues (Spy0247 and Spy0351) were identified of B. subtilis SpoIIIJ (Errington et al., 1992), a probable Lpp that has recently been suggested to be associated with the export and processing of integral membrane proteins (Tjalsma et al., 2000; Luirink et al., 2001; Yen et al., 2001). Both Spy0247 and Spy0351 are predicted to encode proteins with multiple MSDs in addition to the predicted $\mathrm{N}$ terminal lipid anchor, as in SpoIIIJ (Luirink et al., 2001; Yen et al., 2001). Likewise, two homologous putative Lpps of the SpoIIIJ family have been identified in the pneumococcal genome (Tettelin et al., 2001). The functional significance of the probable $\mathrm{N}$-terminal lipidation of these SpoIIIJ family proteins is difficult to predict given that they are also integral membrane proteins. However, the lipid anchor may serve to correctly orientate an $\mathrm{N}$-terminal domain and it is noted that several proven Lpps also have additional MSDs (see Methods).

In addition to the above, at least two probable Lpps (Spy1390 and Spy2037) may function as extracytoplasmic folding catalysts in S. pyogenes. Both proteins are homologous to the recently described pneumococcal putative maturase PpmA (Overweg et al., 2000a, b) and to the proven Lpps PrsA of B. subtilis and PrtM of Lactococcus lactis (Haandrikman et al., 1991; Kontinen \& Sarvas, 1993). Collectively these proteins belong to the type C family of peptidyl-prolyl isomerases (Rudd et al., 1995) which appear to direct correct protein folding. Thus these Lpps may act as folding catalysts or chaperones during protein export, although it is not clear whether this function is likely to be general or linked to the export of specific proteins. Since chaperones are likely to be required to interact with their cognate proteins as they emerge from the cytoplasmic membrane, the predicted localization of Lpps immediately adjacent to the external face of the membrane is consistent with this role. A further putative Lpp, peptidyl-prolyl isomerase, is discussed below.

Spy1558 is a member of the family of thioredoxin proteins and two homologous thioredoxin family members were identified in the pneumococcal genome (Tettelin et al., 2001). Both Spy1558 and its pneumococcal putative Lpp homologue SP0659 are situated adjacent to genes encoding putative exported peptide methionine sulfoxide reductases. These enzymes repair the damage to proteins that results from the oxidation of methionine residues to methionine sulfoxide and this catalytic activity requires an associated thioredoxin regenerating system (Lowther et al., 2000). This may therefore be the role of the adjacent Lpp.

In addition to Lpps belonging to the functional categories described above, three surface enzymes (LppC acid phosphatase; Spy0210, which contains a domain suggesting it may be a protease of the transglutaminase family; and Spy0857, a putative peptidoglycan hydrolase), two conserved hypothetical proteins and an ORF with no significant homologues were identified as probable Lpps.

Three putative Lpp sequences were identified that conformed with the PS00013 pattern but not the G + LPP pattern and, as such, warrant further consideration. Of these, the putative pullulanase Spy1972 is unusual in the length of its signal sequence n-region and also contains a C-terminal LPXTG motif that may provide an alternative wall-anchoring mechanism (Janulczyk \& Rasmussen, 2001). The signal peptide features of Spy1361 were consistent with an h-region preceding the possible lipobox but this sequence was excluded by G + LPP due to the presence of a glutamine residue within the h-region. Spy1361 was noted to contain a 300 aa domain homologous to the leucine-rich repeat region of L. monocytogenes internalin A that is preceded by an $\mathrm{N}$-terminal domain containing four histidine-triad motifs (HXXHXH) which is homologous to PhtE of $S$. pneumoniae (Adamou et al., 2001). The signal peptide features of the third protein Spy2066, a putative dipeptidase, are ambiguous. Thus without further evidence for the Lpp nature of these proteins, it is prudent to consider these three proteins as possible rather than probable Lpps.

\section{Possible 'false-negatives' not identified by pattern searching the $S$. pyogenes genome}

A combination of strategies was used to locate possible Lpp sequences missed using either of the above pattern searches (i.e. possible 'false-negatives'). These included analyses of the $S$. pyogenes genome annotation, searches for homologues of pneumococcal Lpps, searches through PEDANT and very low stringency BLAST searches $(E=100)$ using a representative selection of the signal sequences for the probable Lpps identified herein (Table 4). These analyses identified six possible false-negatives that warrant further consideration.

Four additional SBPs that may be possible Lpps were identified. One such sequence was Spy0163 which, as noted above, is a paralogue of Spy1228. This sequence was revealed by BLAST searches with Spy1228 and the pneumococcal putative Lpp SP0845 but found to be annotated without five potential $\mathrm{N}$-terminal amino acids, including an alternative start methionine and two lysines that would complete the signal peptide n-region. This revised signal peptide for Spy0163 matches the G + LPP pattern and both the sequence motifs identified by Rosati et al. (1999) are present. Secondly, Spy1592 was identified as a putative SBP. The signal sequence of this protein contains a lipobox sequence which was excluded by the pattern searches because of an asparagine at the -4 position. However, the corresponding ORF (99\% amino acid identity) in the $S$. pyogenes Manfredo genome (http://www.sanger.ac.uk/Projects/S_pyogenes/) contains a serine at this position, suggesting this putative SBP may indeed be a Lpp in some strains. Likewise, the putative amino acid SBP 
Spy0778 and Spy1306, a homologue of pneumococcal MalX, were excluded as their possible lipobox sequences contained proline in the -4 position. As this is incompatible with both PS00013 and the G+LPP patterns, these SBPs should not be considered to be Lpps until proven otherwise, particularly as some SBPs (including the Spy0713 AdcA metal binding protein homologue) are evidently not Lpps (Turner et al., 1999; Claverys, 2001).

The $S$. pyogenes genome also contains an additional possible Lpp, peptidyl-prolyl isomerase of the cyclophilin family, Spy0457, which is highly homologous to the pneumococcal SP0771 putative Lpp. Again, this sequence was excluded by the pattern searches as the putative lipobox sequence contains an asparagine at the -4 position. As with Spy1592, the corresponding ORF (99\% amino acid identity) in the S. pyogenes Manfredo genome contains the acceptable amino acid serine at this position and so this protein is likely to be a Lpp, at least in some strains of $S$. pyogenes. As discussed above, peptidyl-prolyl isomerase Lpp may assist in the folding of exported protein(s).

Finally, Spy2033 was identified as a possible falsenegative. This sequence has been shown to contain a functional signal sequence directing either protein export or cell surface localization (Gibson \& Caparon, 2002). The deposited Spy2033 sequence has an abnormally long 64 aa signal sequence. However, it is notable that the h-region ends in a putative lipobox cysteine which is preceded by sequence consistent with a canonical Lpp signal peptide $\left(\mathrm{M}_{41}\right.$ KFKKVLVIPALALAATCFLTAC $_{63}$ ). The alternative start at $\mathrm{M}_{41}$ is also consistent with sequence alignments of Spy2033 with its homologue, the Streptococcus cristatus putative Lpp TptA. Thus it may be that the annotation of this sequence needs verification.

\section{Conclusions}

It is evident from the data herein that the identification of putative Lpp genes has been greatly facilitated by computer-assisted sequence analysis methods. Pattern searches such as those described here are useful in application to the published bacterial genomes (and other deposited sequences) and, with appropriate software [e.g. MacVector (Janulczyk \& Rasmussen, 2001)], can also be applied to the publicly available unfinished genome sequences. Searches with the PS00013 pattern are useful in identifying possible Lpps, although more extensive analysis (Table 4 and unpublished observations) suggests that a significant proportion of these are unlikely to be Lpps (i.e. they are false-positives). This lack of stringency associated with the PS00013 pattern was recognized during the annotation of the S. pneumoniae genome as putative Lpps were initially identified using PS00013, then the dataset refined using a novel hidden Markov model (Tettelin et al., 2001). Moreover, the ISREC ProfileScan Server (http://hits.isb-sib.ch/ cgi-bin/hits_motifscan) for pattern matching is noted to consider PS00013 as a low specificity 'pattern that matches very frequently'. The present analysis demonstrates the benefits of employing a taxon-specific approach to increase the stringency of the pattern used for Lpp identification. The G + LPP pattern described herein allows probable Lpps of Gram-positive bacteria (excluding Mollicutes) to be identified with greater confidence. Moreover, the G + LPP pattern identifies proven and putative Lpp signal sequences that are not detected by searching with the PS00013 pattern. Application of the G+LPP pattern to the genomes of $S$. pyogenes and $B$. subtilis confirms that putative Lpps represent an abundant (at least $\sim 1.5 \%$ of the proteome) class of cell envelope proteins. Functional predictions suggest that the Lpps of $S$. pyogenes may contribute to the virulence of this important pathogen and so these proteins may represent targets for novel therapeutic interventions. However, it must be emphasized that in silico analyses such as these are of importance primarily as a foundation for experimental analyses.

\section{ACKNOWLEDGEMENTS}

The authors are extremely grateful for the help of Professor Howard Jenkinson (University of Bristol) in reviewing and providing many constructive comments on an early draft of the manuscript. The authors work on bacterial lipoproteins is supported by The Wellcome Trust (project grant 056042).

\section{REFERENCES}

Adamou, J. E., Heinrichs, J. H., Erwin, A. L. \& 10 other authors (2001). Identification and characterization of a novel family of pneumococcal proteins that are protective against sepsis. Infect Immun 69, 949-958.

Albert, I., Rutherford, A. W., Grav, H., Kellermann, J. \& Michel, H. (1998). The $18 \mathrm{kDa}$ cytochrome c553 from Heliobacterium gestii: gene sequence and characterization of the mature protein. Biochemistry 37, 9001-9008.

Alloing, G., De Philip, P. \& Claverys, J.-P. (1994). Three highly homologous membrane-bound lipoproteins participate in oligopeptide transport by the Ami system of the Gram-positive Streptococcus pneumoniae. J Mol Biol 241, 44-58.

Altschul, S. F., Madden, T. L., Schaffer, A. A., Zhang, J. H., Zhang, Z., Miller, W. \& Lipman, D. J. (1997). Gapped BLAST and PSIBLAST: a new generation of protein database search programs. Nucleic Acids Res 25, 3389-3402.

Andersen, A. B. \& Hansen, E. B. (1989). Structure and mapping of antigenic domains of protein antigen b, a 38,000-molecular weight protein of Mycobacterium tuberculosis. Infect Immun 57, 24812489.

Antelmann, H., Tjalsma, H., Voigt, B., Ohlmeier, S., Bron, S., van Dijl, J. M. \& Hecker, M. (2001). A proteomic view of genome-based signal peptide predictions. Genome Res 11, 1484-1502.

Ashbridge, K. R., Booth, R. J., Watson, J. D. \& Lathigra, R. (1989). Nucleotide sequence of the $19 \mathrm{kDa}$ antigen gene from Mycobacterium tuberculosis. Nucleic Acids Res 17, 1249.

Bengtsson, J., Tjalsma, H., Rivolta, C. \& Hederstedt, L. (1999). Subunit II of Bacillus subtilis cytochrome $\mathrm{c}$ oxidase is a lipoprotein. J Bacteriol 181, 685-688.

Braun, V. \& Wu, H. C. (1994). Lipoproteins, structure, function, biosynthesis and model for protein export. New Compr Biochem 27, 319-341. 
Campbell, D. J. \& Shastri, N. (1998). Bacterial surface proteins recognized by $\mathrm{CD} 4+\mathrm{T}$ cells during murine infection with Listeria monocytogenes. J Immunol 161, 2339-2347.

Chambaud, I., Wróblewski, H. \& Blanchard, A. (1999). Interactions between mycoplasma lipoproteins and the host immune system. Trends Microbiol 7, 493-499.

Chanter, N., Ward, C. L., Talbot, N. C., Flanagan, J. A., Binns, M., Houghton, S. B., Smith, K. C. \& Mumford, J. A. (1999). Recombinant hyaluronate associated protein as a protective immunogen against Streptococcus equi and Streptococcus zooepidemicus challenge in mice. Microb Pathog 27, 133-143.

Claros, M. G. \& von Heijne, G. (1994). TopPred II : an improved software for membrane protein structure predictions. CABIOS 10, 685-686.

Claverys, J.-P. (2001). A new family of high-affinity ABC manganese and zinc permeases. Res Microbiol 152, 231-243.

Cleavinger, C. M., Kim, M. F. \& Wise, K. S. (1994). Processing and surface presentation of the Mycoplasma hyorhinis variant lipoprotein VlpC. J Bacteriol 176, 2463-2467.

Cleavinger, C. M., Kim, M. F., Im, J. H. \& Wise, K. S. (1995). Identification of Mycoplasma membrane proteins by systematic TnphoA mutagenesis of a recombinant library. Mol Microbiol 18, 283-293.

Cockayne, A., Hill, P. J., Powell, N. B. L., Bishop, K., Sims, C. \& Williams, P. (1998). Molecular cloning of a 32-kilodalton lipoprotein component of a novel iron-regulated Staphylococcus epidermidis ABC transporter. Infect Immun 66, 3767-3774.

Cossart, P. \& Jonquieres, R. (2000). Sortase, a universal target for therapeutic agents against Gram-positive bacteria? Proc Natl Acad Sci U S A 97, 5013-5015.

Cserzo, M., Wallin, E., Simon, I., von Heijne, G. \& Elofsson, A. (1997). Prediction of transmembrane alpha-helices in prokaryotic membrane proteins: the Dense Alignment Surface method. Protein Eng 10, 673-676.

Dartois, V., Djavakhishvili, T. \& Hoch, J. A. (1997). KapB is a lipoprotein required for KinB signal transduction and activation of the phosphorelay to sporulation in Bacillus subtilis. Mol Microbiol 26, 1097-1108.

Demchick, P. \& Koch, A. L. (1996). The permeability of the wall fabric of Escherichia coli and Bacillus subtilis. J Bacteriol 178, 768-773.

Dijkstra, A. J. \& Keck, W. (1996). Peptidoglycan as a barrier to transenvelope transport. J Bacteriol 178, 5555-5562.

D'Orazio, M., Folcarelli, S., Mariani, F., Colizzi, V., Rotilio, G. \& Battistoni, A. (2001). Lipid modification of the $\mathrm{Cu}, \mathrm{Zn}$ superoxide dismutase from Mycobacterium tuberculosis. Biochem J 359, 17-22.

Edman, M., Jarhede, T., Sjostrom, M. \& Wieslander, A. (1999). Different sequence patterns in signal peptides from mycoplasmas, other gram-positive bacteria, and Escherichia coli: a multivariate data analysis. Proteins 35, 195-205.

Erbeznik, M., Ray, M., Dawson, K. A. \& Strobel, H. J. (1998a). Xylose transport by the anaerobic thermophile Thermoanaerobacter ethanolicus and the characterization of a D-xylose-binding protein. Curr Microbiol 37, 295-300.

Erbeznik, M., Strobel, H. J., Dawson, K. A. \& Jones, C. R. (1998b). The D-xylose binding protein, XylF, from Thermoanaerobacter ethanolicus 39E: cloning, molecular analysis, and expression of the structural gene. J Bacteriol 180, 3570-3577.

Errington, J., Appleby, L., Daniel, R. A., Goodfellow, H., Partridge, S. R. \& Yudkin, M. D. (1992). Structure and function of the spoIIIJ gene of Bacillus subtilis: a vegetatively expressed gene that is essential for $\sigma^{\mathrm{G}}$ activity at an intermediate stage of sporulation. $J$ Gen Microbiol 138, 2609-2618.

Falquet, L., Pagni, M., Bucher, P., Hulo, N., Sigrist, C. J. A., Hofmann, K. \& Bairoch, A. (2002). The PROSITE database: its status in 2002. Nucleic Acids Res 30, 235-238.

Ferretti, J. J., McShan, W. M., Ajdic, D. \& 20 other authors (2001). Complete genome sequence of an M1 strain of Streptococcus pyogenes. Proc Natl Acad Sci US A 98, 4658-4663.

Frishman, D., Albermann, K., Hani, J., Heumann, K., Metanomski, A., Zollner, A. \& Mewes, H. W. (2001). Functional and structural genomics using PEDANT. Bioinformatics 17, 44-57.

Fujiwara, Y., Oka, M., Hamamoto, T. \& Sone, N. (1993). Cytochrome-c-551 of the thermophilic bacterium PS3, DNAsequence and analysis of the mature cytochrome. Biochim Biophys Acta 1144, 213-219.

Gase, K., Liu, G. W., Bruckmann, A., Steiner, K., Ozegowski, J. \& Malke, H. (1997). The LppC gene of Streptococcus equisimilis encodes a lipoprotein that is homologous to the e(P4) outer membrane protein from Haemophilus influenzae. Med Microbiol Immunol 186, 63-73.

Gibson, C. M. \& Caparon, M. G. (2002). Alkaline phosphatase reporter transposon for identification of genes encoding secreted proteins in Gram-positive microorganisms. Appl Environ Microbiol 68, 928-932.

Haake, D. A. (2000). Spirochaetal lipoproteins and pathogenesis. Microbiology 146, 1491-1504.

Haandrikman, A. J., Kok, J. \& Venema, G. (1991). Lactococcal proteinase maturation protein PrtM is a lipoprotein. J Bacteriol 173, 4517-4525.

Hamilton, A., Harrington, D. \& Sutcliffe, I. C. (2000). Characterisation of acid phosphatase activities in the equine pathogen Streptococcus equi. Syst Appl Microbiol 23, 325-329.

Harrington, D. J., Greated, J. S., Chanter, N. \& Sutcliffe, I. C. (2000). Identification of lipoprotein homologues of pneumococcal PsaA in the equine pathogens Streptococcus equi and Streptococcus zooepidemicus. Infect Immun 68, 6048-6051.

Herrmann, A., Schlösser, A., Schmid, R. \& Schneider, E. (1996). Biochemical identification of a lipoprotein with maltose-binding activity in the thermoacidophilic Gram-positive bacterium Alicyclobacillus acidocaldarius. Res Microbiol 147, 733-737.

Hofmann, K. \& Stoffel, W. (1993). TMbase-a database of membrane spanning protein segments. Biol Chem Hoppe-Seyler 374, 166.

Hülsmann, A., Lurz, R., Scheffel, F. \& Schneider, E. (2000). Maltose and maltodextrin transport in the thermoacidophilic Gram-positive bacterium Alicyclobacillus acidocaldarius is mediated by a high-affinity transport system that includes a maltose binding protein tolerant to low $\mathrm{pH}$. J Bacteriol 182, 6292-6302.

Inukai, M., Takeuchi, M., Shimizu, K. \& Arai, M. (1978). Mechanism of action of globomycin. J Antibiotics 31, 1203-1205. Janulczyk, R. \& Rasmussen, M. (2001). Improved pattern for genome-based screening identifies novel cell wall-attached proteins in gram-positive bacteria. Infect Immun 69, 4019-4026.

Janulczyk, R., Pallon, J. \& Bjorck, L. (1999). Identification and characterization of a Streptococcus pyogenes ABC transporter with multiple specificity for metal cations. Mol Microbiol 34, 596-606.

Jenkinson, H. F., Baker, R. A. \& Tannock, G. W. (1996). A bindinglipoprotein-dependent oligopeptide transport system in Streptococcus gordonii essential for uptake of hexa- and heptapeptides. J Bacteriol 178, 68-77. 
Kempf, B., Gade, J. \& Bremer, E. (1997). Lipoprotein from the osmoregulated $\mathrm{ABC}$ transport system OpuA of Bacillus subtilis: purification of the glycine betaine binding protein and characterization of a functional lipidless mutant. J Bacteriol 179, 6213-6220.

Klein, D., Somorja, R. L. \& Lau, P. C. K. (1988). Distinctive properties of signal sequences from bacterial lipoproteins. Protein Eng 2, 15-20.

Kontinen, V. P. \& Sarvas, M. (1993). The PrsA lipoprotein is essential for protein secretion in Bacillus subtilis and sets a limit for high-level secretion. Mol Microbiol 8, 727-737.

Leskelä, S., Wahlstrom, E., Kontinen, V. P. \& Sarvas, M. (1999). Lipid modification of prelipoproteins is dispensable for growth but essential for efficient protein secretion in Bacillus subtilis: characterization of the lgt gene. Mol Microbiol 31, 1075-1085.

Lowther, W. T., Brot, N., Weissbach, H., Honek, J. F. \& Matthews, B. W. (2000). Thiol-disulfide exchange is involved in the catalytic mechanism of peptide methionine sulfoxide reductase. Proc Natl Acad Sci U S A 97, 6463-6468.

Luirink, J., Samuelsson, T. \& de Gier, J.-W. (2001). YidC/ Oxa1p/Alb3: evolutionarily conserved mediators of membrane protein assembly. FEBS Lett 501, 1-5.

Malke, H. (1998). Cytoplasmic membrane lipoprotein LppC of Streptococcus equisimilis functions as an acid phosphatase. Appl Environ Microbiol 64, 2439-2442.

Nair, J., Rouse, D. A. \& Morris, S. L. (1993). Nucleotide sequence analysis and serologic characterization of a 27-kilodalton $\mathrm{Myco-}$ bacterium intracellulare lipoprotein. Infect Immun 61, 1074-1081.

Navarre, W. W. \& Schneewind, O. (1999). Surface proteins of gram-positive bacteria and mechanisms of their targeting to the cell wall envelope. Microbiol Mol Biol Rev 63, 174-229.

Neubauer, H., Pantel, I., Lindgren, P. E. \& Götz, F. (1999). Characterization of the molybdate transport system ModABC of Staphylococcus carnosus. Arch Microbiol 172, 109-115.

Nielsen, H. \& Krogh, A. (1998). Prediction of signal peptides and signal anchors by a hidden Markov model. Int Syst Mol Biol 6, 122-130.

Nielsen, J. B. K. \& Lampen, J. O. (1982). Membrane-bound penicillinases in gram-positive bacteria. J Biol Chem 257, 4490-4495.

Nielsen, J. B. K. \& Lampen, J. O. (1983). Beta-lactamase-III of Bacillus cereus 569 - membrane lipoprotein and secreted protein. Biochemistry 22, 4652-4656.

Nielsen, H., Engelbrecht, J., Brunak, S. \& von Heijne, G. (1997). Identification of prokaryotic and eukaryotic signal peptides and prediction of their cleavage sites. Protein Eng 10, 1-6.

Nyström, S. \& Wieslander, A. (1992). Isoprenoid modification of proteins distinct from membrane acyl proteins in the prokaryote Acholeplasma laidlawii. Biochim Biophys Acta 1107, 39-43.

Nyström, S., Johansson, K. E. \& Wieslander, A. (1986). Selective acylation of membrane-proteins in Acholeplasma laidlawii. Eur J Biochem 156, 85-94.

Overweg, K., Kerr, A., Sluijter, M., Jackson, M. H., Mitchell, T. J., De Jong, A. P. J. M., De Groot, R. \& Hermans, P. W. M. (2000a). The putative proteinase maturation protein A of Streptococcus pneumoniae is a conserved surface protein with potential to elicit protective immune responses. Infect Immun 68, 4180-4188.

Overweg, K., Pericone, C. D., Verhoef, G. G. C., Weiser, J. N., Meiring, H. D., De Jong, A.P. J. M., De Groot, R. \& Hermans, P. W. M. (2000b). Differential protein expression in phenotypic variants of Streptococcus pneumoniae. Infect Immun 68, 4604-4610.
Pahl, A. \& Keller, U. (1994). Streptomyces chrysomallus FKBP-33 is a novel immunophilin consisting of 2 FK506 binding domains: its gene is transcriptionally coupled to the FKBP-12 gene. EMBO J 13, 3472-3480.

Petit, C. M., Brown, J. R., Ingraham, K., Bryant, A. P. \& Holmes, D. J. (2001). Lipid modification of prelipoproteins is dispensable for growth in vitro but essential for virulence in Streptococcus pneumoniae. FEMS Microbiol Lett 200, 229-233.

Podbielski, A. \& Leonard, B. A. B. (1998). The group A streptococcal dipeptide permease (Dpp) is involved in the uptake of essential amino acids and affects the expression of cysteine protease. Mol Microbiol 28, 1323-1334.

Podbielski, A., Pohl, B., Woischnik, M., Korner, C., Schmidt, K. H., Rozdzinski, E. \& Leonard, B. A. B. (1996). Molecular characterization of group A streptococcal (GAS) oligopeptide permease (Opp) and its effect on cysteine protease production. Mol Microbiol 21, 1087-1099.

Pyrowolakis, G., Hofmann, D. \& Herrmann, R. (1998). The subunit $\mathrm{b}$ of the $\mathrm{F}_{0} \mathrm{~F}_{1}$-type ATPase of the bacterium Mycoplasma pneumoniae is a lipoprotein. J Biol Chem 273, 24792-24796.

Qi, H. Y., Sankaran, K., Gan, K. \& Wu, H. C. (1995). Structurefunction relationship of bacterial prolipoprotein diacylglyceryl transferase: functionally significant conserved regions. J Bacteriol 177, 6820-6824.

Razin, S., Yogev, D. \& Naot, Y. (1998). Molecular biology and pathogenicity of mycoplasmas. Microbiol Mol Biol Rev 62, 1094-1156.

Rosati, S., Pozzi, S., Robino, P., Montinaro, B., Conti, A., Fadda, M. \& Pittau, M. (1999). P48 major surface antigen of Mycoplasma agalactiae is homologous to a MALP product of Mycoplasma fermentans and belongs to a selected family of bacterial lipoproteins. Infect Immun 67, 6213-6216.

Rudd, K. E., Sofia, H. J., Koonin, E. V., Plunkett, G., Lazar, S. \& Rouviere, P. E. (1995). A new family of peptidyl-prolyl isomerases. Trends Biochem Sci 20, 12-14.

Sakamoto, J., Shibata, T., Mine, T., Miyahara, R., Torigoe, T., Noguchi, S., Matsushita, K. \& Sone, N. (2001). Cytochrome $c$ oxidase contains an extra charged amino acid cluster in the new type of respiratory chain in the amino-acid-producing Grampositive bacterium Corynebacterium glutamicum. Microbiology 147, 2865-2871.

Sankaran, K. \& Wu, H. C. (1995). Bacterial prolipoprotein signal peptidase. Methods Enzymol 248, 169-180.

Sankaran, K., Gupta, S. D. \& Wu, H. C. (1995). Modification of bacterial lipoproteins. Methods Enzymol 250, 683-697.

Schlösser, A. \& Schrempf, H. (1996). A lipid-anchored binding protein is a component of an ATP-dependent cellobiose/ cellotriose-transport system from the cellulose degrader Streptomyces reticuli. Eur J Biochem 242, 332-338.

Sutcliffe, I. C. \& Russell, R. R. B. (1995). Lipoproteins of Grampositive bacteria. J Bacteriol 177, 1123-1128.

Sutcliffe, I. C., Tao, L., Ferretti, J. J. \& Russell, R. R. B. (1993). MsmE, a lipoprotein involved in sugar transport in Streptococcus mutans. J Bacteriol 175, 1853-1855.

Terao, Y., Kawabata, S., Kunitomo, E., Nakagawa, I. \& Hamada, S. (2002). Novel laminin-binding protein of Streptococcus pyogenes, Lbp, is involved in adhesion to epithelial cells. Infect Immun 70, 993-997.

Tettelin, H., Nelson, K. E., Paulsen, I. T. \& 36 other authors (2001). Complete genome sequence of a virulent isolate of Streptococcus pneumoniae. Science 293, 498-506. 
Tjalsma, H., Kontinen, V. P., Prágai, Z., Wu, H. Y., Meima, R., Venema, G., Bron, S., Sarvas, M. \& van Dijl, J. M. (1999a). The role of lipoprotein processing by signal peptidase II in the Grampositive eubacterium Bacillus subtilis: signal peptidase II is required for the efficient secretion of alpha-amylase, a nonlipoprotein. J Biol Chem 274, 1698-1707.

Tjalsma, H., Zanen, G., Venema, G., Bron, S. \& van Dijl, J. M. (1999b). The potential active site of the lipoprotein-specific (type II) signal peptidase of Bacillus subtilis. J Biol Chem 274, 28191-28197.

Tjalsma, H., Bolhuis, A., Jongbloed, J. D. H., Bron, S. \& van Dijl, J. M. (2000). Signal peptide-dependent protein transport in Bacillus subtilis: a genome-based survey of the secretome. Microbiol Mol Biol Rev 64, 515-547.

Turner, M. S., Woodberry, T., Hafner, L. M. \& Giffard, P. M. (1999). The BspA locus of Lactobacillus fermentum BR11 encodes an L-cystine uptake system. J Bacteriol 181, 2192-2198.

von Heijne, G. (1989). The structure of signal peptides from bacterial lipoproteins. Protein Eng 2, 531-534.
Vosloo, W., Tippoo, P., Hughes, J. E., Harriman, N., Emms, M., Beatty, D. W., Zappe, H. \& Steyn, L. M. (1997). Characterisation of a lipoprotein in Mycobacterium bovis (BCG) with sequence similarity to the secreted protein MPB70. Gene 188, 123-128.

Witke, C. \& Götz, F. (1995). Cloning and nucleotide sequence of the signal peptidase II (Lsp) gene from Staphylococcus carnosus. FEMS Microbiol Lett 126, 233-239.

Yen, M.-R., Harley, K. T., Tseng, Y.-H. \& Saier, M. H., Jr (2001). Phylogenetic and structural analyses of the oxa1 family of protein translocases. FEMS Microbiol Lett 204, 223-231.

Young, D. B. \& Garbe, T. R. (1991). Lipoprotein antigens of Mycobacterium tuberculosis. Res Microbiol 142, 55-65.

Zhao, X. J. \& Wu, H. C. (1992). Nucleotide sequence of the Staphylococcus aureus signal peptidase II (Lsp) gene. FEBS Lett 299, 80-84.

Received 11 January 2002; revised 5 March 2002; accepted 14 March 2002. 